\title{
The "Long-Sheath" Technique in Percutaneous Aortic Balloon Valvuloplasty
}

\author{
PATRICK W. SERRUYS, M.D., FACC, CARLO DI MARIO, M.D., RENE KONING, MD,* \\ PIM J DE FEYTER, M.D., KEVIN J. BEATT, MRCP.,** and
}

MARCEL VAN DEN BRAND, M.D.

From the Thoraxcenter, Erasmus University, Rotterdam, The Netherlands

A new $100 \mathrm{~cm}$ long 16.5 French valvuloplasty introducer was used in 12 consecutive patients (mean age 73 years, five males and seven females) undergoing aortic balloon valvuloplasty for severe aortic stenosis. The long-sheath was introduced into the ascending aorta along the stiff part of an exchange guidewire. The valvuloplasty procedure, which included a complete diagnostic catheterization in three patients, lasted $113 \pm 47 \mathrm{~min}(211$ \pm 81 min in the previous 18 procedures performed with a conventional approach, $P<0.05$ ). Introduction of balloon catheters $(3 \times 12 \mathrm{~mm}$ trefoil balloon in the 12 cases and $2 \times 19 \mathrm{~mm}$ bifoil balloon in 2 of these cases) was possible in all patients and an increased stability of the balloon during inflation was observed. No systemic embolization or vascular complications occurred at the puncture site. The long-sheath technique appears to be a valuable adjunct for aortic valvuloplasty in that it provides easier and quicker access for even the largest balloons and additional support and stability during balloon inflation. In our experience, this reduced the practical difficulties and the duration of the procedure. (J Interven Cardiol 1988:1:2)

\section{Introduction}

Balloon valvuloplasty provides an alternative treatment to surgery in patients with severe aortic stenosis, especially in those who are considered to be a high surgical risk. ${ }^{1,2}$ In this paper we report the results of 12 aortic balloon valvuloplasties where a long-sheath technique was applied.

* Dr. Rene Koning is the recipient of the Fellowship of the University Hospital University of Rouen.

**Dr. Kevin Beatt is the recipient of the joint Fellowship of the British and Netherlands Heart Foundations.

Address for reprints: Patrick W. Serruys, M.D., FACC, Catheterization Laboratory, Thoraxcenter, Erasmus University, P.O. Box 1738, 3000 DR Rotterdam, The Netherlands.

Submitted for publication April 18, 1988; accepted May 11, 1988.

\section{Methods}

Between March 1986 and April 1987 eighteen patients were treated by aortic valvuloplasty using the conventional approach. ${ }^{3}$

Beginning April 198711 patients (mean age 78, range $60-88$ years) with degenerative calcific aortic valve stenosis and one 16-year-old patient with a congenitally bicuspid stenotic aortic valve underwent balloon valvuloplasty using the longsheath technique. ${ }^{4}$ Before starting the valvuloplasty procedure, $1.0 \mathrm{mg}$ of atropine and 5,000 I.U. of heparin were administered intravenously. In all patients retrograde ventricular catheterization was performed via the femoral route by introducing either an Amplatz or Judkins left coronary catheter through a 9 French sheath. Subsequently, an exchange guidewire was advanced into the left 
ventricular cavity. In two patients we used a straight $0.038^{\prime \prime}, 260 \mathrm{~cm}$ long guidewire (Cordis Corporation, Miami), with its soft tip manually fashioned into a large $\mathrm{j}$-shape to prevent myocardial damage. In the remaining 10 patients a $0.035^{\prime \prime}$, $300 \mathrm{~cm}$ long "back-up" guidewire (Schneider Shiley AG) was used. The wire has a long stiff proximal part which lies between the introduction site and the subaortic valve region, and facilitates the introduction of sheaths and balloon catheters through tortuous peripheral vessels and the stenotic aortic valve; the most distal $7-12 \mathrm{~cm}$ is designed with a $\mathrm{j}$-shaped very flexible tip so as not to traumatize the ventricle. A $100 \mathrm{~cm}$ long 16.5 French valvuloplasty introducer (Schneider Shiley AG) was passed into the femoral artery along the guidewire. This introducer consists of a polyurethane dilator and a Teflon sheath connected to a proximal system to prevent retrograde bleeding. This adjustable adapter (Fig. 1) is formed by a self-sealing diabolus-shape silicon valve and a proximal screw-seal. A side arm, connected to the transparent chamber in which the silicon valve is located, allows intermittent flushing of both the valve and the internal lumen of the sheath and enables the recording of the hydraulically transmitted pressure from the proximal tip of the sheath.

Despite the frequently tortuous and severely narrowed iliac and femoral vessels (Fig. 2A) commonly seen in elderly patients, the introducer could be easily inserted into the ascending aorta in

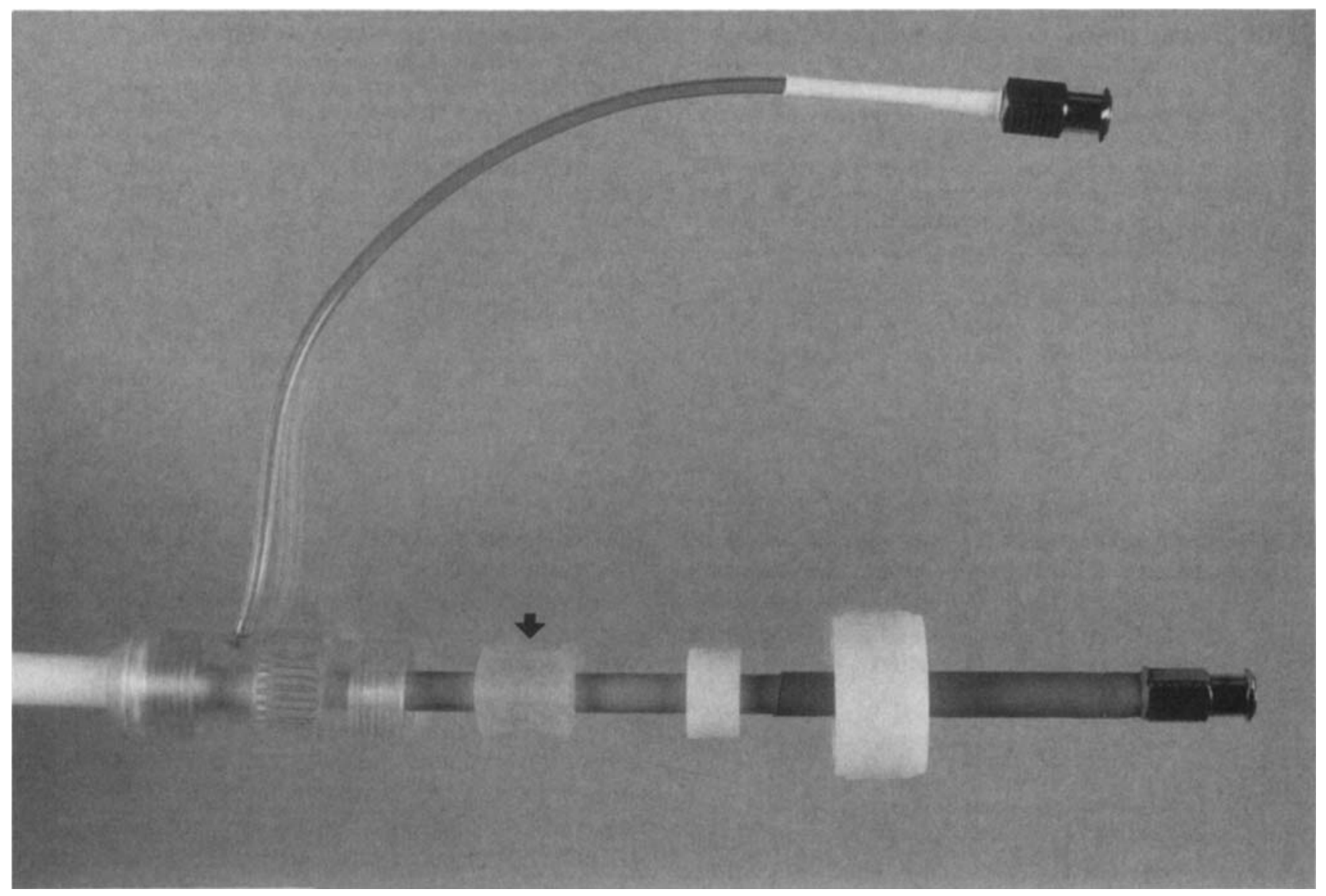

Figure 1. The proximal, adjustable adapter of the 16.5 French, $100 \mathrm{~cm}$ long valvuloplasty introducer (Schneider Shiley AG) consists of a distal self-sealing system, with a diabolus-shape silicon valve (indicated with arrows in the picture), and a proximal screw-seal. The side-arm allows intermittent flushing with heparinized solution during the procedure of both the transparent adapter and the inner lumen of the catheter. 


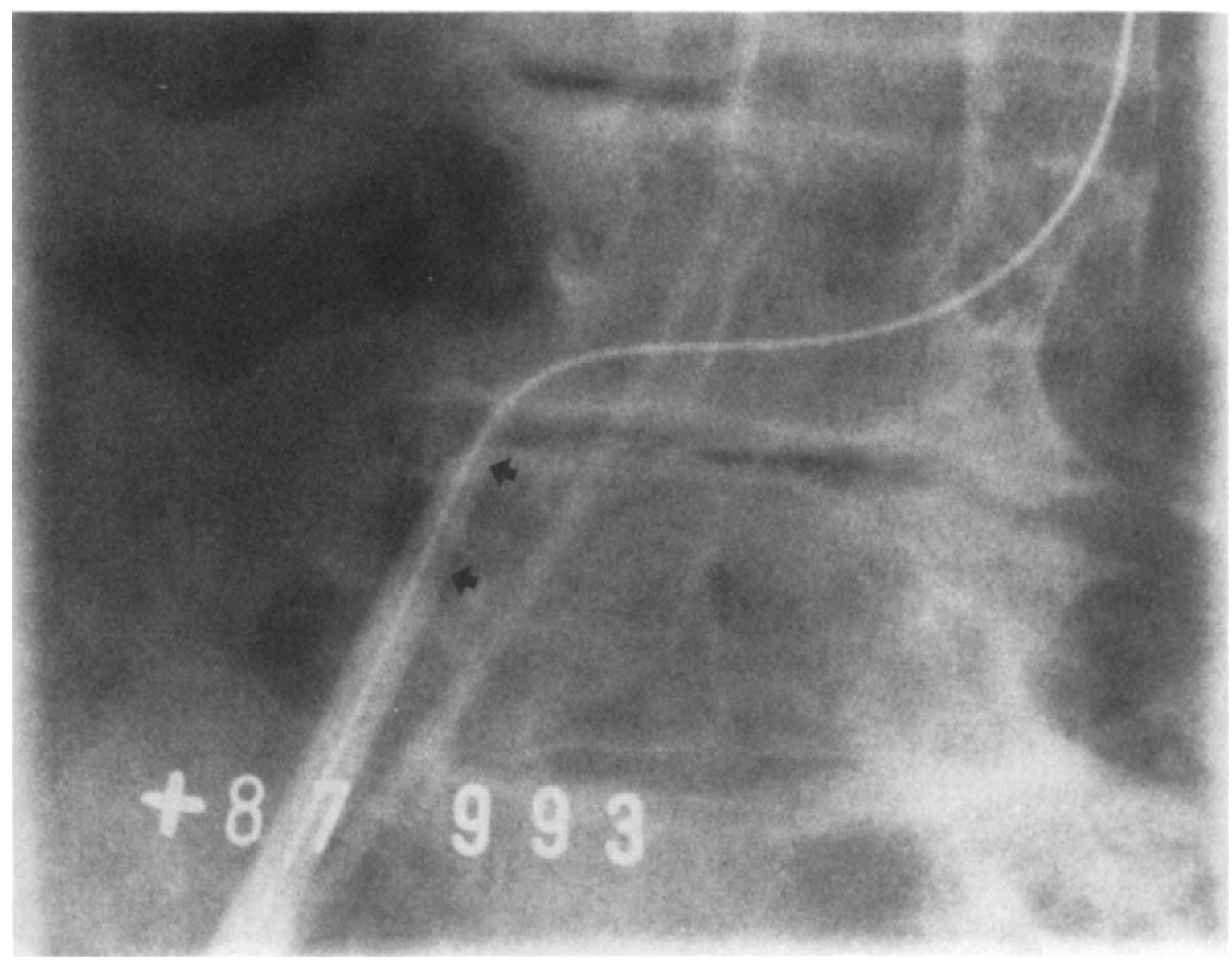

Figure 2A. The progression of the valvuloplasty introducer through the tortuous iliac vessel along the stiffer part of the back-up guidewire. In the same patient (case 1) looping and bending of the balloon catheter prevented its direct insertion across the aortic orifice with a previous standard approach. Gradual tapering of the tip of the inner dilatator is indicated with arrows.

all patients (Fig. 2B). The excellent trackability of the system is believed to be related to both the gradual tapering of the tip of the inner dilator and the support provided by the stiff guidewire. Although advancement of the long-sheath across the aortic orifice had been suggested, we positioned the introducer just above the aortic valve (Fig. 2C). With the sheath left in place and the dilator removed, we easily introduced the balloon catheter across the aortic valve aided by the stiff guidewire and the external sheath, which prevented possible looping or kinking of the balloon catheter in the iliac or femoral vessels or above the aortic cusps. The presence of the sheath just above the balloon prevented the to-and-fro motion of the balloon across the aortic valve, which frequently occurs during balloon inflation (Fig. 2D). A mean of 1.5 balloons per patient were used, with various shapes and diameters ranging from circular balloons of $15 \mathrm{~mm}$, trefoil balloons of $3 \times 12 \mathrm{~mm}$ (area $3.8 \mathrm{~cm}^{2}$ ) to bifoil balloons $2 \times 19 \mathrm{~mm}$ (area $6.4 \mathrm{~cm}^{2}$ ) and in one case a $25 \mathrm{~mm}$ circular (Mansfield, Scientific, Boston) balloon. In case of balloon replacement, the balloon catheters could be easily removed with the long-sheath left in place, even if balloon rupture had occurred during inflation. After reversal of the residual anticoagulant effect of the heparin by the appropriate infusion of protamine sulphate intravenously, the sheath was removed and hemostasis achieved by careful bi- 


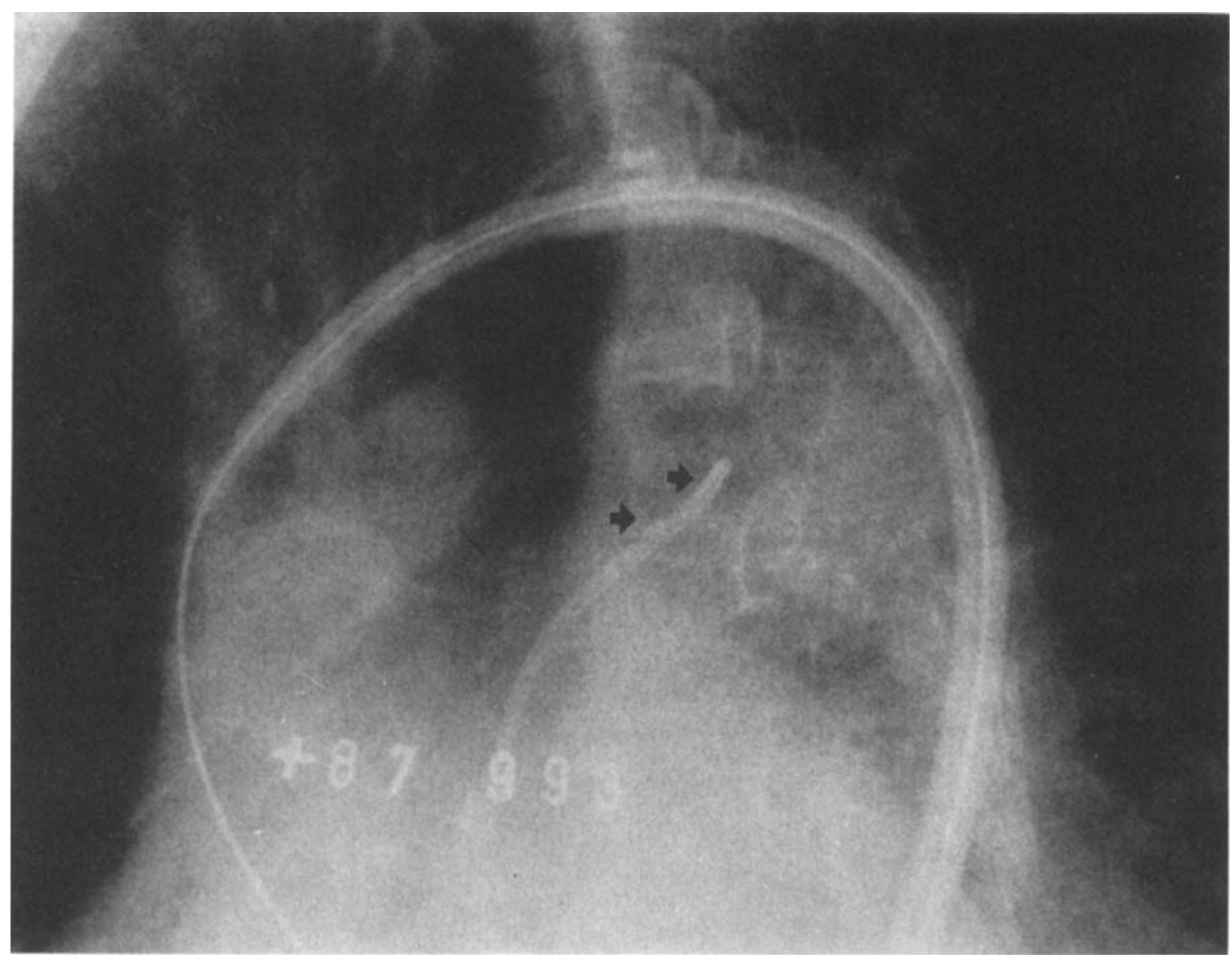

Figure 2B. The further progression of the valvuloplasty introducer across the aortic arch along the guidewire. Arrows indicate the ? French Swan Ganz catheter positioned in the pulmonary artery trunk.

manual inguinal compression for at least $30 \mathrm{~min}$ (mean $45 \mathrm{~min}$ ) after removal of the sheath.

\section{Results}

Immediate Hemodynamic Results and Early Complications. Immediate hemodynamic results are summarized in Table 1. A slight increase in aortic valve insufficiency (from $1+$ to $2+/ 4+$ ) was observed in two patients. Patient 1 was successfully dilated using a $3 \times 12 \mathrm{~mm}$ trefoil balloon with the long-sheath technique, after having undergone a valvuloplasty procedure the previous day using a conventional approach. This had resulted in minimal hemodynamic improvement because the aortic valve could not be crossed with a balloon catheter larger than a $3 \times 5 \mathrm{~mm}$ trefoil balloon.

Patient 4, 77-years old, with coexistent severe stenosis of the left main stem, an occluded right coronary artery and a left ventricular ejection fraction of $14 \%$, developed irreversible cardiogenic shock at the end of the first inflation. At autopsy, no cardiac or vascular damage seemingly related to the procedure could be observed.

Patient 5 developed a short run of ventricular tachycardia during balloon inflation, while no major procedure-related ventricular arrhythmias were observed in the remaining patients. Patient 8 developed complete atrioventricular block immediately after the insertion of the back-up guidewire, which eventually required implantation of a permanent pacemaker. Transient bundle branch 


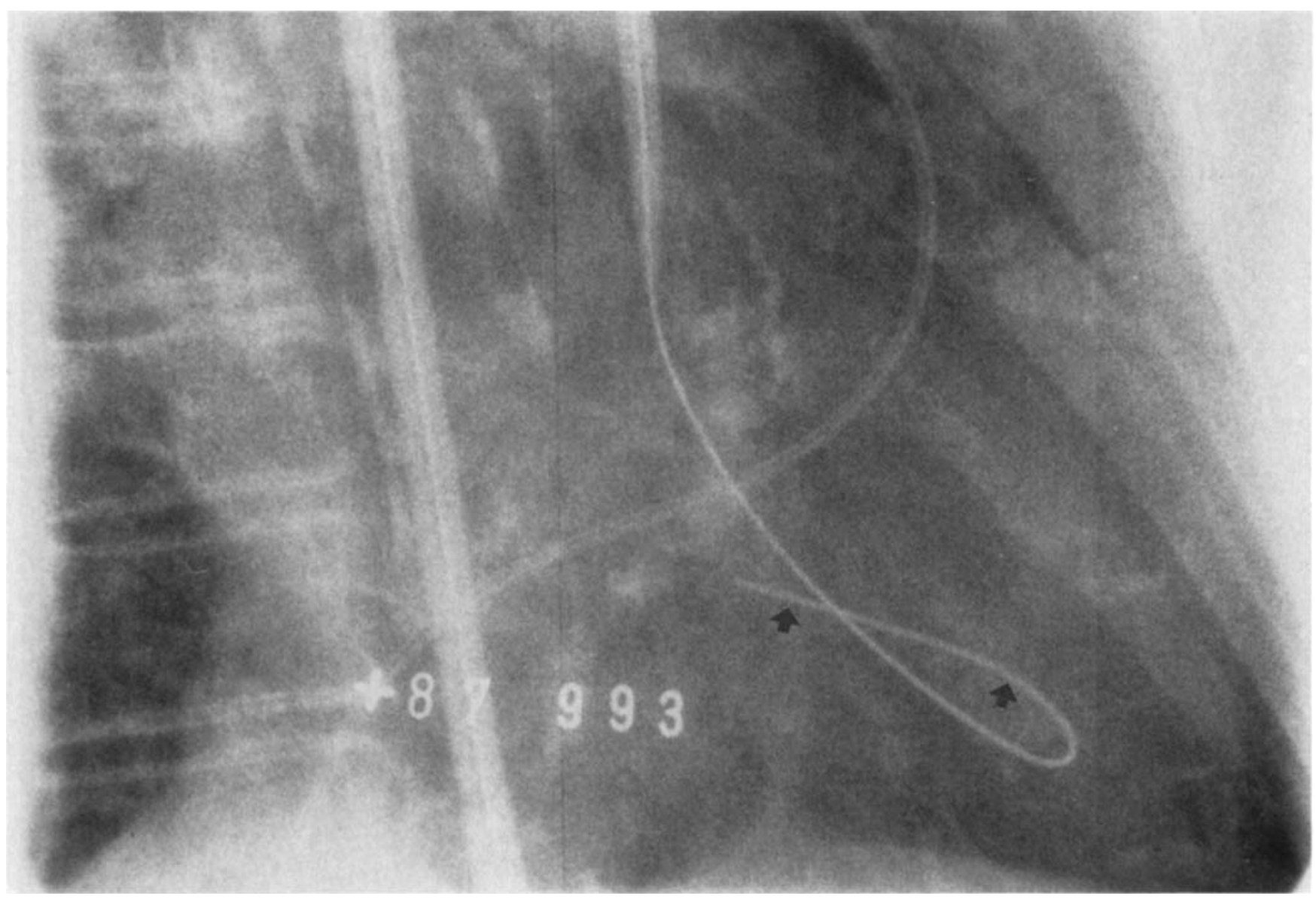

Figure $2 \mathrm{C}$. When the introducer reaches the heavily calcified aortic valve, the inner part is removed and the balloon catheter introduced and advanced across the aortic valve. Arrows indicate the $\mathrm{j}$-shaped distal floppy tip of the "backup" guidewirc.

block was observed during the procedure in patients 1 and 10 . Only one patient experienced a brief loss of consciousness during inflation (patient 12). None of the patients developed hematomas, bleeding or vascular complications at the puncture site, during or following the procedure nor during the subsequent hospitalization.

\section{Observations Based on the Results of the Previous 18 aortic Valvuloplasties}

In the previous 18 aortic balloon valvuloplasty procedures (March 1986-April 1987) the balloon catheter was inserted directly into the femoral artery. Continuous inguinal compression was required during the prodedure. This group of patients was comparable for age (67 vs 73 years in the long-sheath group), mean aortic gradient (68 vs 75 $\mathrm{mmHg}$ ) and mean aortic valve area $(0.51$ vs 0.47 $\mathrm{cm}^{2}$ ) prior to dilatation. The hemodynamic benefit of dilatation was also similar in this group, the mean aortic valve gradient decreasing from 68 to $43 \mathrm{mmHg}$ and the valve area from 0.51 to 0.78 $\mathrm{cm}^{2}$. However, the mean duration of the procedure significantly decreased (from $211 \pm 81 \mathrm{~min}$ to $113 \pm 47 \mathrm{~min}, \mathrm{P}<0.05)$, despite a comparable number of patients ( 5 and 3 respectively) who underwent a complete diagnostic catheterization, including selective coronary angiography, in the same session.

Three of the initial series of 18 patients required surgical intervention at the puncture site, two because of the development of femoral pseudoaneurysms and one in order to remove a balloon rem- 


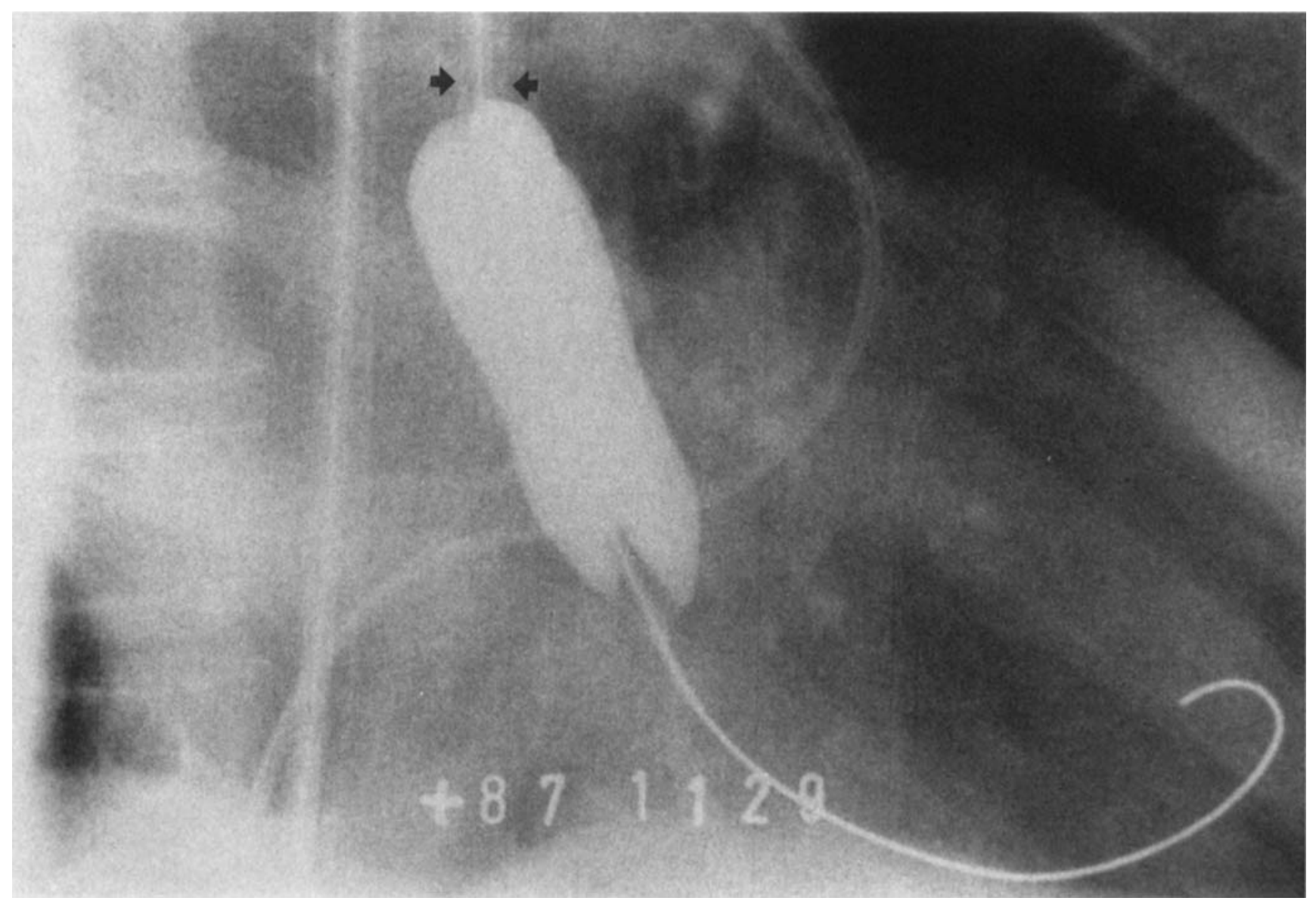

Figure 2D. A $3 \times 12,40 \mathrm{~mm}$ long trefoil balloon (Schneider Shiley AG) is inflated across the calcific stenotic aortic valve. The presence of the sheath (arrows), just above the balloon, prevents possible to-and-fro motion during inflation, allowing the use of shorter balloons.

nant from the femoral artery after balloon rupture. Two additional patients required multiple blood infusions because of inguinal hematomas and in most patients blood infusion was felt necessary because of major bleeding during removal and introduction of the largest balloons.

Unsuccessful introduction of a $3 \times 12 \mathrm{~mm}$ trefoil balloon catheter into the femoral artery or across the aortic valve occurred in three patients of the initial series.

\section{Discussion}

Up to now, the most frequently reported procedure-related complication during aortic valve balloon dilatation has been related to damage at the arterial introduction site and mainly concerns the introduction of the larger balloons required to achieve effective hemodynamic results. Cribier et $\mathrm{al}^{5}$ have reported three false aneurysms and one arteriovenous shunt requiring surgical correction, and one death related to peripheral ischemia in 92 patients. However, if "minor" damage is considered (i.e., large inguinal hematomas requiring blood transfusions or evacuation) the local complication rate rises to $13.5 \%$ (Data from $635 \mathrm{pa}$ tients collected by the French Registry). ${ }^{6}$

Several alternative approaches have been proposed: surgical cut-down to the brachial or femoral artery, ${ }^{7,8}$ temporary subclavian vascular graft, ${ }^{9}$ anterograde transseptal positioning of the balloon catheter, ${ }^{10}$ and independent introduction of two 


\section{“LONG-SHEATH" BALLOON VALVULOPLASTY}

Table 1. Hemodynamic Data Before and After Aortic Valve Balloon Dilatation

\begin{tabular}{|c|c|c|c|c|c|c|c|c|c|c|c|c|c|c|c|}
\hline \multirow[b]{2}{*}{ Patients } & \multirow[b]{2}{*}{ Age } & \multirow[b]{2}{*}{ Sex } & \multirow[b]{2}{*}{ Balloon } & \multicolumn{2}{|c|}{ LVPSP } & \multicolumn{2}{|c|}{ LVEDP } & \multicolumn{2}{|c|}{ PSG } & \multicolumn{2}{|c|}{ MSG } & \multicolumn{2}{|c|}{ AF } & \multicolumn{2}{|c|}{ AVA } \\
\hline & & & & B & $\mathbf{A}$ & B & A & B & A & B & A & $\mathbf{B}$ & A & B & $\mathbf{A}$ \\
\hline 1 & 16 & $\mathbf{M}$ & $\begin{array}{l}3 \times 10(\mathrm{TF}) \\
3 \times 12(\mathrm{TF})\end{array}$ & 242 & 148 & 11 & 6 & 142 & 50 & 90 & 43 & 299 & 382 & 0.71 & 1.31 \\
\hline 2 & 60 & $\mathbf{M}$ & $3 \times 12(\mathrm{TF})$ & 234 & 151 & 14 & 2 & 90 & 40 & 75 & 31 & 191 & 195 & 0.49 & 0.79 \\
\hline 3 & 71 & $\mathbf{M}$ & $\begin{array}{l}3 \times 9(\mathrm{TF}) \\
3 \times 12(\mathrm{TF})\end{array}$ & 221 & 163 & 8 & 5 & 100 & 84 & 70 & 58 & 289 & 290 & 0.78 & 0.86 \\
\hline 4 & 77 & $\mathbf{M}$ & $3 \times 12$ (TF) & 115 & - & 32 & - & 40 & - & 38 & - & 110 & - & 0.40 & - \\
\hline 5 & 77 & $\mathbf{M}$ & $3 \times 12(\mathrm{TF})$ & 150 & 116 & 20 & 18 & 54 & 24 & 37 & 28 & 119 & 175 & 0.44 & 0.75 \\
\hline 6 & 88 & $\mathrm{~F}$ & $3 \times 12(\mathrm{TF})$ & 180 & 181 & 11 & 11 & 72 & 37 & 89 & 49 & 133 & 151 & 0.31 & 0.49 \\
\hline 7 & 79 & $F$ & $3 \times 12$ (TF) & 291 & 193 & 30 & 17 & 127 & 59 & 109 & 62 & 171 & 231 & 0.37 & 0.66 \\
\hline 8 & 84 & $F$ & $3 \times 12$ (TF) & 231 & 199 & 14 & 12 & 120 & 24 & 90 & 40 & 132 & 130 & 0.31 & 0.46 \\
\hline 9 & 80 & $\mathrm{~F}$ & $\begin{array}{l}3 \times 8 \text { (TF) } \\
3 \times 12 \text { (TF) }\end{array}$ & 223 & 192 & 4 & 8 & 66 & 47 & 56 & 53 & 127 & 205 & 0.38 & 0.64 \\
\hline 10 & 84 & $\mathbf{F}$ & $\begin{array}{l}3 \times 12(\mathrm{TF}) \\
2 \times 19(\mathrm{BF})\end{array}$ & 180 & 173 & 29 & 8 & 87 & 23 & 91 & 28 & 168 & 258 & 0.40 & 1.10 \\
\hline 11 & 75 & $F$ & $3 \times 12(\mathrm{TF})$ & 228 & 202 & 10 & 15 & 77 & 30 & 80 & 53 & 200 & 242 & 0.50 & 0.80 \\
\hline 12 & 84 & $\mathrm{~F}$ & $\begin{array}{l}3 \times 12(\mathrm{TF}) \\
2 \times 19(\mathrm{BF}) \\
25 \mathrm{~mm}\end{array}$ & 200 & 172 & 7 & 8 & 69 & 36 & 73 & 41 & 205 & 210 & 0.60 & 0.85 \\
\hline $\begin{array}{l}\text { Mean } \\
\pm \mathrm{SD}\end{array}$ & & & & $\begin{array}{r}207.9 \\
46.4\end{array}$ & $\begin{array}{c}171.8 \\
26\end{array}$ & $\begin{array}{r}15.8 \\
9.6\end{array}$ & $\begin{array}{l}10 \\
5.1\end{array}$ & $\begin{array}{l}87 \\
30.5\end{array}$ & $\begin{array}{l}41.2 \\
18.3\end{array}$ & $\begin{array}{l}74.8 \\
21.9\end{array}$ & $\begin{array}{l}44.2 \\
11.9\end{array}$ & $\begin{array}{r}178.6 \\
62.7\end{array}$ & $\begin{array}{r}224.5 \\
69.8\end{array}$ & $\begin{array}{l}0.47 \\
0.15\end{array}$ & $\begin{array}{l}0.79 \\
0.24\end{array}$ \\
\hline & & & & \multicolumn{2}{|c|}{$\mathrm{p}<0.005$} & \multicolumn{2}{|c|}{ ns } & \multicolumn{2}{|c|}{$\mathrm{p}<0.002$} & \multicolumn{2}{|c|}{$p<0.005$} & \multicolumn{2}{|c|}{$p<0.05$} & \multicolumn{2}{|c|}{$p<0.002$} \\
\hline
\end{tabular}

TF: trefoil; BF: bifoil; LVPSP: left ventricular peak-systolic pressure ( $\mathrm{mmHg}$ ); LVEDP: left ventricular end-diastolic pressure (mmHg); PSG: peak systolic aortic gradient (mmHg); MSG: mean systolic aortic gradient (mmHg); AF: systolic aortic flow (ml/s); AVA: aortic valve area $\left(\mathrm{cm}^{2}\right)$.

balloon catheters. " However, most of the proposed methods have the disadvantage of further increasing the duration and complexity of a procedure often poorly tolerated by the critically ill patients generally considered for aortic valvuloplasty. Vascular damage has also been reported using a surgical brachial approach and the double balloon technique. The use of the 16.5 French arterial sheath, despite the large diameter, has not been associated with any vascular complication. This was somewhat unexpected as the use of intraaortic balloon pump catheters of similar size has an established incidence of peripheral vascular complication, but this may be more related to the duration of use rather than the size of the catheter. Although data of the previous series of patients is interesting and serves as a guide to the functional result that may be anticipated, direct comparison may be misleading, because of the learning curve generally observed with new techniques. However, there was a marked decrease in the duration of the valvuloplasty procedure and the possibility of immediate passage across the aortic valve with large balloons in all patients should be emphasized. On the contrary, unsuccessful attempts at balloon catheter introduction into the femoral artery or across the aortic valve were observed in our previous patients ${ }^{3}$ and in other reported series. ${ }^{12}$ The use of a stiff guidewire facilitates the insertion of the long-sheath and the combined use of these devices avoids looping and kinking of the balloon catheter when attempting to cross the valve. The length of the flexible tip is critical because if it extends too proximally into the supravalvular aorta, tracking control is lost, the balloon catheter can no longer be directed to the aortic valve orifice and the guidewire may be expelled from the left ventricle. Conversely, if it is too short the stiffer part may lie deep within the ventricular cavity and cause myocardial damage. One case of complete atrioventricular block, a rare but well-known complication of aortic valvuloplasty procedures, 


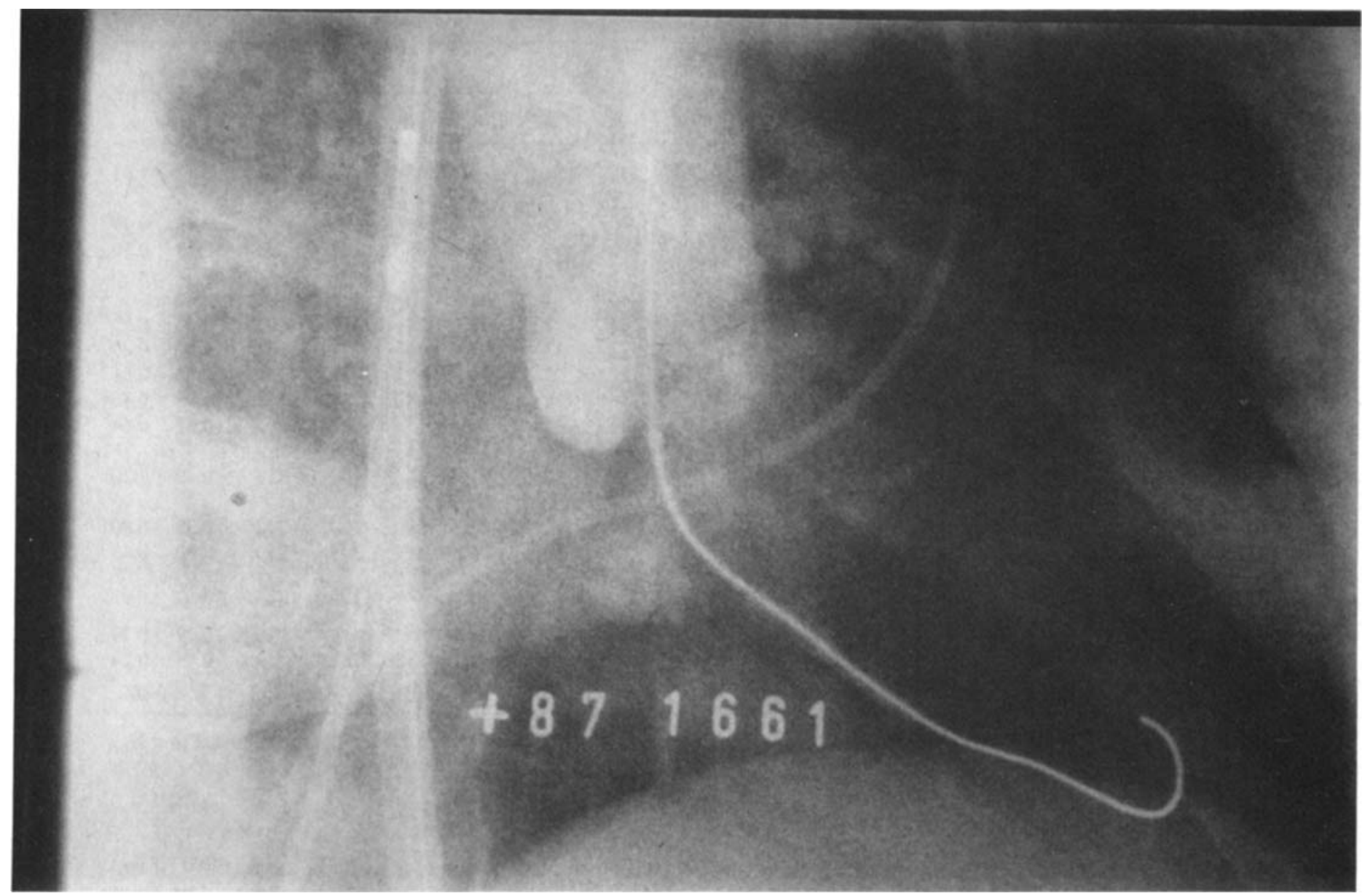

Figure 3. Example of an aortogram obtained by means of the sheath.

previously described, after balloon inflation, ${ }^{5}$ and occurred during insertion of a back-up guidewire with a relatively short $(7 \mathrm{~cm})$ flexible tip.

The presence of a side-arm on the sheath allows high quality hydrodynamic transmission of the pressure curve in the ascending aorta throughout the procedure and provides an accurate measurement of peak and mean systolic transvalvular aortic gradients without the need of a second arterial catheter. An additional advantage of the longsheath is that an aortogram of good quality can be obtained during and following the balloon inflation so that the presence of aortic regurgitation produced by the procedure can easily be assessed (Fig. 3).

In both the long-sheath group (Table 1) and the control group there were patients whose valve area was less than $0.7 \mathrm{~cm}^{2}$ despite some hemodynamic improvement and the use of relatively large sized balloons. This limitation of the procedure, already recognized by others, ${ }^{2,5,6}$ does not appear to be directly altered by the use of the long-sheath, which can, however, allow passage of the largest balloons currently available.

\section{Conclusion}

The long-sheath technique in aortic balloon valvuloplasty minimizes trauma at the arterial puncture site, reduces the frequency of vascular complications, decreases the duration of the procedure, facilitates the passage of multiple balloon cath- 


\section{"LONG-SHEATH" BALLOON VALVULOPLASTY}

eters, even with the largest sizes and improves the stability of the balloon during inflation.

\section{References}

1. Cribier A, Saoudi N, Berland J, Savin T, Rocha P, Letac B. Percutaneous transluminal valvuloplasty of acquired aortic stenosis in elderly patients: an alternative to valve replacement? Lancet 1986; I:63-67.

2. McKay RG, Safian RD, Lock JE, Diver DJ, Berman AD, Warren SE, Come PC, Baim DS, Mandell VE, Royal HD, Grossman W. Assessment of left ventricular and aortic valve function after aortic balloon valvuloplasty in adult patients with critical aortic stenosis. Circulation 1987 75:192-203

3. Di Mario C, Beatt KJ, van den Brand M, de Feyter PJ, Essed CE, Serruys PW. Percutaneous balloon dilatation in elderly patients with calcific aortic stenosis. Immediate hemodynamic assessment and short-term clinical followup. Br Heart J 1987; 58:644-652.

4. Meier B, Friedli B, Segesser L, Valvuloplasty with trefoil and bifoil balloons and the long-sheath technique. Herz 1988; 13:1-13.

5. Cribier A, Savin T, Berland J, Rocha P, Mechmeche R, Saoudi M, Behar P, Letac B. Percutaneous transluminal balloon valvuloplasty of adult aortic stenosis: report of 92 cases. J Am Coll Cardiol 1987; 9:381-386,
6. Berland J, Cribier A, Letac B, Guermonprey JL. Percutaneous aortic valvuloplasty in adults: immediate results of the French Registry. (abstract) Eur Heart J 1987; 8(Suppl 2):241.

7. Isner JM, Salem BN, Denoyers MR, Hougen TJ, MacKey WC, Pandian NG, Eichhorn EJ, Konstam MA, Levine HJ. Treatment of calcific aortic stenosis by balloon valvuloplasty. Am J Cardiol 1987; 59:313-317,

8. Slama M, Vahanian A, Michel PL, Cornier B, van Vliet H, Dermine P, Acar J. Brachial approach for aortic balloon valvuloplasty of aortic stenosis in the elderly (abstract). Eur Heart J 1987; 8(Suppl 2):240.

9. Heyndrick GR, Nellens P, Andries E, Paulus WJ. Improved technique for valve access and pressure monitoring during percutaneous transluminal valvuloplasty for aortic stenosis. (abstract) Eur Heart J 1987; 8(Suppl 2): 240 .

10. Grollier G, Commeau PH, Agostini D, Durand C, Foucault JP, Potier JC. Anterograde percutaneous valvuloplasty in a case of severe calcific aortic stenosis. Eur Heart J 1987; 8:190-193.

11. Dorros G. Levine RF, King JF, Jankr LM. Percutaneous transluminal valvuloplasty in calcific aortic stenosis: the double balloon technique. Cath Cardiovase Diagn 1987; 13:151-156.

12. Drobinski G, Lechat $P$, Metzger JP, Lepailleur C, Vacheron A, Grosgogeat $Y$. Results of percutaneous catheter valvuloplasty for calcified aortic stenosis in the elderly. Eur Heart J 1987; 8:322-328. 